\section{(2) \\ BRAZIILIAN JOURNAL \\ OF MEDICAL AND BIOLOGICAL RESEARCH}

www.bjournal.com.br
ISSN 0100-879X

Volume 45 (6) 473-564 June 2012

BIOMEDICAL SCIENCES

AND

CLINICAL INVESTIGATION

Braz J Med Biol Res, May 2012, Volume 45(6) 531-536

doi: $10.1590 / \mathrm{S} 0100-879 X 2012007500047$

Participation of the NO/cGMP/K+ATP pathway in the antinociception induced by Walker tumor bearing in rats

A.L.R. Barbosa, C.A. Pinheiro, G.J. Oliveira, J.N.L. Torres, M.O. Moraes, R.A. Ribeiro, M.L. Vale and M.H.L.P. Souza

The Brazilian Journal of Medical and Biological Research is partially financed by

\section{Q QNPPq}

da Ciência e Tecnologia

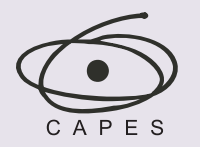

Ministério da Educação

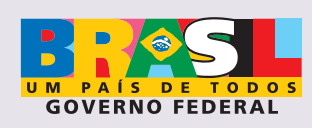

DTFAPESP

plore High - Performance MS Orbitrap Technology
Institutional Sponsors

† SHIMADzu
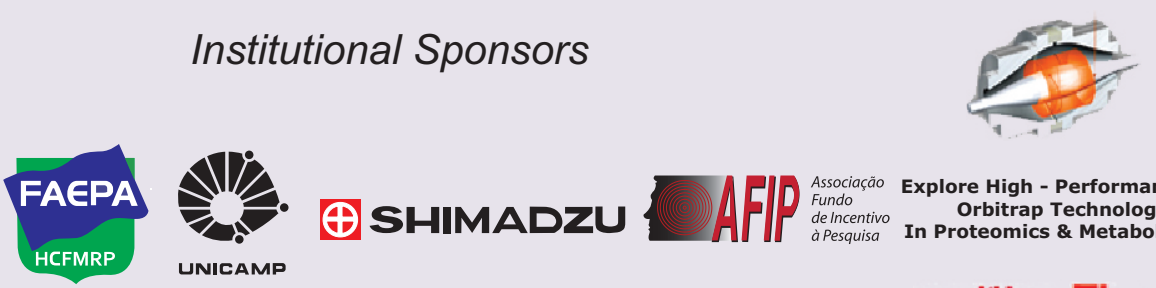

Associaçăo
Fundo 


\title{
Participation of the NO/cGMP/K+ATP pathway in the antinociception induced by Walker tumor bearing in rats
}

\author{
A.L.R. Barbosa, C.A. Pinheiro, G.J. Oliveira, J.N.L. Torres, \\ M.O. Moraes, R.A. Ribeiro, M.L. Vale and M.H.L.P. Souza \\ Departamento de Fisiologia e Farmacologia, Faculdade de Medicina, \\ Universidade Federal do Ceará, Fortaleza, CE, Brasil
}

\begin{abstract}
Implantation of Walker 256 tumor decreases acute systemic inflammation in rats. Inflammatory hyperalgesia is one of the most important events of acute inflammation. The L-arginine/NO/cGMP/K ${ }^{+} \mathrm{ATP}$ pathway has been proposed as the mechanism of peripheral antinociception mediated by several drugs and physical exercise. The objective of this study was to investigate a possible involvement of the NO/cGMP/K ${ }^{+} \mathrm{ATP}$ pathway in antinociception induced in Walker 256 tumor-bearing male Wistar rats (180-220 g). The groups consisted of 5-6 animals. Mechanical inflammatory hypernociception was evaluated using an electronic version of the von Frey test. Walker tumor (4th and 7th day post-implantation) reduced prostaglandin $\mathrm{E}_{2^{-}}\left(\mathrm{PGE}_{2}, 400 \mathrm{ng} / \mathrm{paw}\right.$; $50 \mu \mathrm{L}$; intraplantar injection) and carrageenan-induced hypernociception (500 $\mu \mathrm{g} / \mathrm{paw} ; 100 \mu \mathrm{L}$; intraplantar injection). Walker tumor-induced analgesia was reversed $\left(99.3 \%\right.$ for carrageenan and $77.2 \%$ for $\left.\mathrm{PGE}_{2}\right)$ by a selective inhibitor of nitric oxide synthase (L-NAME; $90 \mathrm{mg} / \mathrm{kg}$, ip) and L-arginine (200 mg/kg, ip), which prevented ( $80 \%$ for carrageenan and $65 \%$ for PGE 2 ) the effect of L-NAME. Treatment with the soluble guanylyl cyclase inhibitor ODQ (100\% for carrageenan and $95 \%$ for PGE $8 \mu \mathrm{g} / \mathrm{paw})$ and the ATP-sensitive $\mathrm{K}^{+}$channel (KATP) blocker glibenclamide $(87.5 \%$ for carrageenan and $100 \%$ for PGE $2 ; 160$ $\mu \mathrm{g} / \mathrm{paw})$ reversed the antinociceptive effect of tumor bearing in a statistically significant manner $(\mathrm{P}<0.05)$. The present study confirmed an intrinsic peripheral antinociceptive effect of Walker tumor bearing in rats. This antinociceptive effect seemed to be mediated by activation of the NO/cGMP pathway followed by the opening of KATP channels.
\end{abstract}

Key words: Walker 246 tumor-bearing rats; Hypernociception; Nitric oxide; Carrageenan

\section{Introduction}

Cancer can induce immunosuppression by an immunosuppressive network extending from the primary tumor site to secondary lymphoid organs and peripheral vessels (1). The Walker 256 tumor is widely utilized in experimental cancer research due to its easy transplantation, lack of regression or strain specificity, and rarity of spontaneous metastases (2). Recently, our group demonstrated that Walker 256 tumor implantation limits mast cell function and vascular events in acute inflammation in rats, without changes in neutrophil migration (3).

Inflammatory hyperalgesia results from the sensitization of primary afferent neurons, which is better described as hypernociception (decrease in nociceptive threshold) in animal models (4). This effect is induced by inflammatory mediators, such as prostaglandins (PGs), which directly sensitize peripheral nociceptive neurons (5-7), and a coordinated cascade of cytokines that precedes the release of other directly acting mediators $(8,9)$. In fact, following the administration of carrageenan in the rat paw, an initial formation of bradykinin occurs, which induces a subsequent proinflammatory cytokine cascade, triggering the release of PGs and sympathetic amines (10).

In inflammatory hypernociception, nitric oxide (NO) activates the guanylate cyclase enzyme, which is directly responsible for an increase in intracellular levels of cyclic guanosine monophosphate (cGMP) (11). Then, cGMP induces the opposite effect of cyclic adenosine monophosphate (cAMP) (12) and promotes antihypernociception. Sachs et al. (13) demonstrated that activation of protein kinase $G$ by cGMP is necessary for the opening of ATP-

Correspondence: M.H.L.P. Souza, Centro de Biomedicina, Faculdade de Medicina, Universidade Federal do Ceará, Rua Cel. Nunes de Melo, 1315, 60430-270 Fortaleza, CE, Brasil. Fax: +55-85-3366-8333. E-mail: souzamar@ufc.br

Received June 1, 2011. Accepted March 13, 2012. Available online March 30, 2012. Published June 4, 2012. 
sensitive $\mathrm{K}^{+}$channels (KATP) in analgesia. However, the role of the $\mathrm{NO} / \mathrm{cGMP} / \mathrm{K}^{+} \mathrm{ATP}$ channel signaling pathway in the tumor bearing-induced decrease in systemic acute inflammation in rats has not been elucidated.

The objective of the present study was to investigate a possible involvement of the $\mathrm{NO} / \mathrm{cGMP} / \mathrm{K}^{+} \mathrm{ATP}$ pathway in the antinociception induced by Walker 256 tumor implantation in rats.

\section{Material and Methods}

\section{Animals}

Wistar rats weighing $180-200 \mathrm{~g}$ were housed in temperature-controlled rooms and received water and food ad libitum. All experiments were conducted in accordance with National Institutes of Health standards and approved by the Committee of Ethics in Animal Research and Care of the Federal University of Ceará (protocol No. 10/11).

\section{Drugs}

Carrageenan, $\mathrm{PGE}_{2}$, L-NAME, aminoguanidine, Larginine, ${ }^{1} \mathrm{H}$-[1,2,4]-oxadiazolo[4,3-a]quinoxalin-1-one (ODQ) and glibenclamide were purchased from Sigma Chemicals (USA). Vehicle solutions consisted of PBS or saline. Glibenclamide was dissolved in vehicle containing saline plus 2\% Tween (Sigma). ODQ was dissolved in saline plus $2 \%$ dimethyl sulfoxide (Sigma). $\mathrm{PGE}_{2}$, carrageenan, L-NAME, aminoguanidine, and L-arginine were dissolved in saline.

\section{Tumor implantation}

Tumor nodules from Walker 256 tumor-bearing rats were excised, gently homogenized with a hand-operated tissue grinder, suspended in sterile lactated Ringer's solution with gentamicin $(20 \%, v / v)$ and adjusted to $10^{6}$ viable tumor cells $/ \mathrm{mL}$. The tumor was implanted by weekly intramuscular injections of $10^{6}$ tumor cells into the left armpit (14). Animals were housed in cages with food/mineral water ad libitum and the effects of Walker 256 tumor bearing was investigated after the 4th or 7th day of tumor implantation.

In preliminary experiments, tumor growth was monitored starting on the 4th day and continuing to the 7th day, reaching maximum growth on the 15th day after inoculation. We also observed that 15 days after tumor inoculation, animal mortality reached $100 \%$ (3). Thus, in this study, we evaluated the effects of tumor bearing on the 4th and 7th day after tumor inoculation.

\section{Mechanical hypernociception}

The term hypernociception (increased nociception) is used to describe the behavioral response induced by mechanical pressure on rats. Hyperalgesia was induced by a subcutaneous injection of carrageenan $(500 \mu \mathrm{g} / \mathrm{paw})$ or $\mathrm{PGE}_{2}$ (400 ng/paw) into the plantar surface of the rat's hindpaw and measured by the paw pressure test as de- scribed by Cunha et al. (15). In the test, the investigator was trained to apply the filaments or the polypropylene tip perpendicularly to the central area of the hindpaw with a gradual increase in pressure. The test consisted of poking a hindpaw to provoke a flexion reflex followed by a clear flinch response after paw withdrawal. Each von Frey filament was applied for approximately 3-4 s to induce the end-point reflex. The weakest filament able to elicit a response was taken to be the mechanical threshold $(\mathrm{g})$.

A digital analgesiometer (Insight, Brazil) with a coneshaped paw-presser with a rounded tip was used to apply a linearly increasing force to the rat's right hindpaw. The nociceptive threshold was measured in the right paw and determined by the average of three consecutive trials recorded before (zero time) and 3 and $4 \mathrm{~h}$ after carrageenan (100 $\mu \mathrm{L} ; 500 \mu \mathrm{g} / \mathrm{paw})$ or $\mathrm{PGE}_{2}(50 \mu \mathrm{L} ; 400$ ng/paw) injection (peak effect). Hyperalgesia was calculated as the difference between these two averages ( $\Delta$ of nociceptive threshold) and is reported in grams. To reduce stress, the rats were habituated to the apparatus one day prior to the experiments (15).

\section{Role of Walker tumor implantation on carrageenan- or $\mathrm{PGE}_{2}$-induced hypernociception}

Four or 7 days after Walker tumor implantation in the left armpit, carrageenan- or $\mathrm{PGE}_{2}$-induced mechanical hypernociception was evaluated in the contralateral paw. The control group received only saline in the left armpit. The nociceptive threshold was measured in the right paw and determined as the average of three consecutive trials recorded before (zero time) and 3 and $4 \mathrm{~h}$ after carrageenan (100 $\mu \mathrm{L} ; 500 \mu \mathrm{g} /$ paw) or PGE 2 (50 $\mu \mathrm{L} ; 400$ ng/paw) injection (peak effect).

\section{Role of NO in the antinociceptive effect induced by Walker tumor implantation}

Four days after Walker tumor implantation in the left armpit, rats were treated with L-NAME (a nonselective nitric oxide synthase (NOS) inhibitor, $90 \mathrm{mg} / \mathrm{kg} ; 0.5 \mathrm{~mL}$; ip) or aminoguanidine (an inducible NOS (iNOS) selective inhibitor, $10 \mathrm{mg} / \mathrm{kg}$; $0.2 \mathrm{~mL}$; subcutaneous injection). After $1 \mathrm{~h}$, carrageenan or $\mathrm{PGE}_{2}$ was administered to the right paw. The other experimental group was treated in the same way, but L-arginine (an NOS substrate, $200 \mathrm{mg} / \mathrm{kg}$; $0.5 \mathrm{~mL}$; intraperitoneal injection) was given $10 \mathrm{~min}$ before L-NAME administration. In the control group of rats without tumors, L-NAME alone was also injected before $\mathrm{PGE}_{2}$ or carrageenan administration. In all experimental groups, the nociceptive threshold was measured in the right paw and determined as described above.

\section{Role of cGMP in antinociceptive effect induced by Walker tumor implantation}

Four days after Walker tumor implantation in the left armpit, the soluble guanylyl cyclase inhibitor ODQ $(8 \mu \mathrm{g} /$ 
paw; $50 \mu \mathrm{L}$; intraplantar injection) or $2 \%$ Tween (diluent) was injected. After 30 min, carrageenan or $\mathrm{PGE}_{2}$ was administered to the right paws of rats. In other groups of rats without tumors, ODQ alone was also injected before carrageenan or $\mathrm{PGE}_{2}$ administration. The nociceptive threshold was then measured in the right paw and determined as described above.

Role of KATP in the antinociceptive effect induced by Walker tumor implantation

Four days after Walker tumor implantation in the left armpit, glibenclamide (a KATP blocker, $160 \mu \mathrm{g} / \mathrm{paw} ; 50$ $\mu \mathrm{L}$; intraplantar injection) or dimethyl sulfoxide (diluent) was injected 30 min before carrageenan and $P E_{2}$ administration in the right paws of rats. In the control group of rats without tumors, glibenclamide alone was also injected before carrageenan or $\mathrm{PGE}_{2}$ administration. The nociceptive threshold was then measured in the right paw and determined as described above.

\section{Statistical analysis}

Data are reported as means \pm SEM for groups of 5 or 6 animals each. Differences between experimental groups were compared by analysis of variance (ANOVA) followed by the Bonferroni $t$-test. The level of significance was set at $\mathrm{P}<0.05$.

\section{Results}

\section{Role of Walker tumor implantation in carrageenan- or PGE $_{2}$-induced hypernociception}

Figure 1 shows that on the 4th or 7 th day after tumor implantation there were significant decreases in both carrageenan- (Panel A) and $\mathrm{PGE}_{2}$-induced (Panel B) hypernociception compared to the control group of rats without tumors.

\section{Involvement of NO in the antinociceptive effect induced by Walker tumor implantation}

Figure 2 shows that pretreatment with L-NAME alone completely reversed the antinociceptive activity of Walker tumor at both 3 and $4 \mathrm{~h}$ after treatment with carrageenan (Panel A, $3 \mathrm{~h}=99.3 \%, 4 \mathrm{~h}=100 \%$ ) or PGE 2 (Panel $\mathrm{B}$, $3 \mathrm{~h}=77.2 \%, 4 \mathrm{~h}=95.7 \%)$. In the control animals without tumors, L-NAME did not increase the inflammatory hypernociception induced by carrageenan (Panel $A$ ) or $\mathrm{PGE}_{2}$ (Panel B). L-arginine was able to reverse the effect of L-NAME on inflammatory hypernociception induced by carrageenan (Panel A) or $\mathrm{PGE}_{2}$ (Panel B). On the other hand, aminoguanidine treatment was not able to change the antinociceptive effect of tumor bearing in $\mathrm{PGE}_{2}$-induced hypernociception (Panel B).

\section{Involvement of cGMP in the antinociceptive effect induced by Walker tumor implantation}

In the carrageenan- (Figure 3, PanelA) or $\mathrm{PGE}_{2}$-induced (Panel B) mechanical hypernociception, ODQ treatment completely reversed Walker tumor-induced antinociceptive activity at both 3 and $4 \mathrm{~h}(\mathrm{P}<0.05)$. In the control animals without tumors, ODQ did not increase the inflammatory hypernociception induced by either carrageenan (Panel A) or $\mathrm{PGE}_{2}$ (Panel B).

\section{Involvement of KATP in the antinociceptive effect induced by Walker tumor implantation}

Figure 4 shows that pretreatment with the specific KATP blocker glibenclamide significantly inhibited Walker tumor-induced antinociceptive activity at both 3 and $4 \mathrm{~h}$
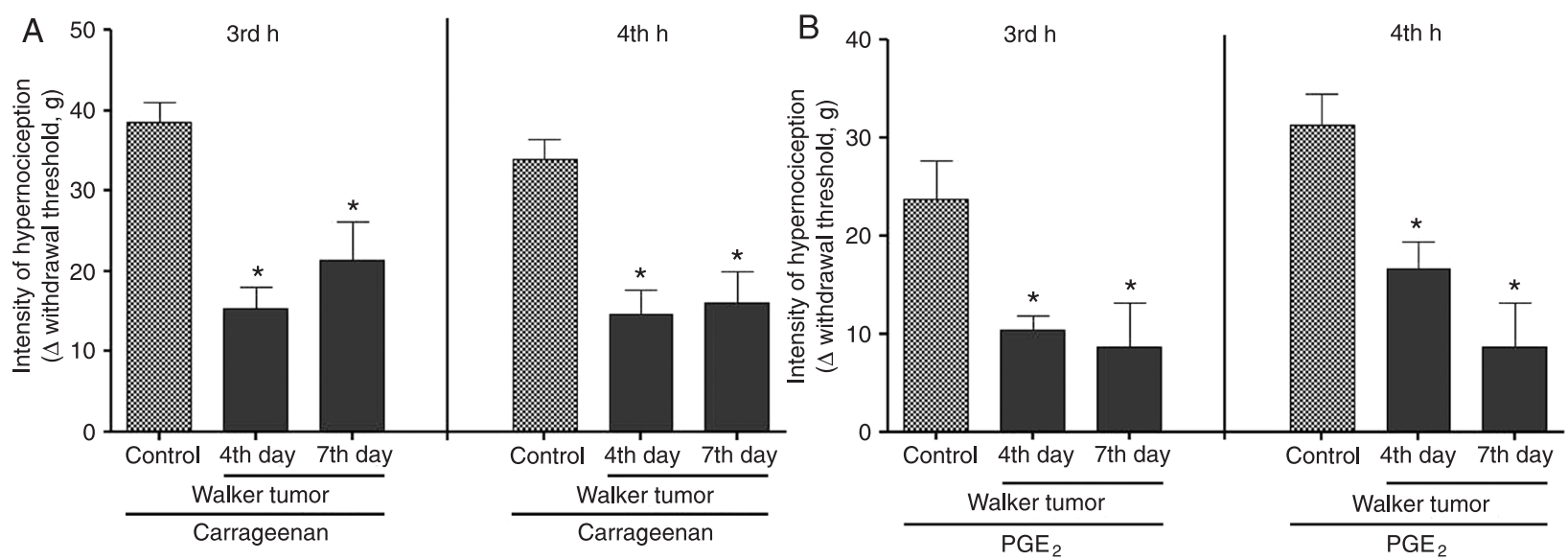

Figure 1. Effect of Walker tumor implantation on carrageenan- or prostaglandin $E_{2}\left(\mathrm{PGE}_{2}\right)$-induced hypernociception. Carrageenan $(500 \mu \mathrm{g} / \mathrm{paw})$ and $\mathrm{PGE}_{2}$ (400 ng/paw) were injected and paw hypernociception was measured after 3 and $4 \mathrm{~h}$ for carrageenan (Panel A) and $\mathrm{PGE}_{2}$ intraplantar injection (Panel $\mathrm{B}$ ). ${ }^{*} \mathrm{P}<0.05$ compared to saline group (ANOVA/Bonferroni test). 
A

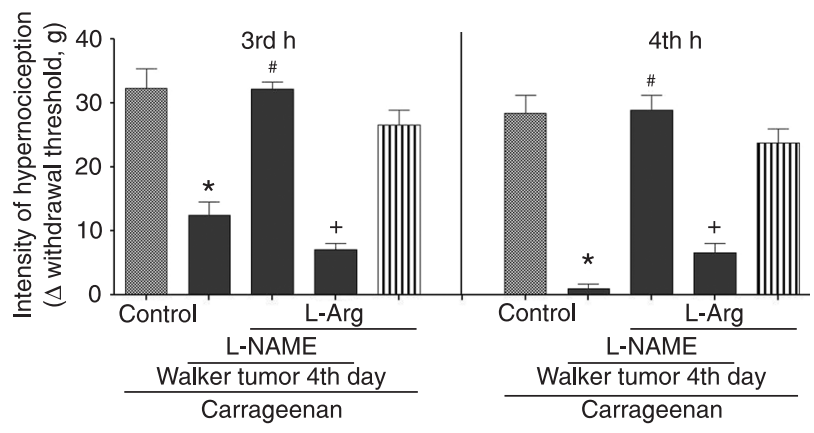

B

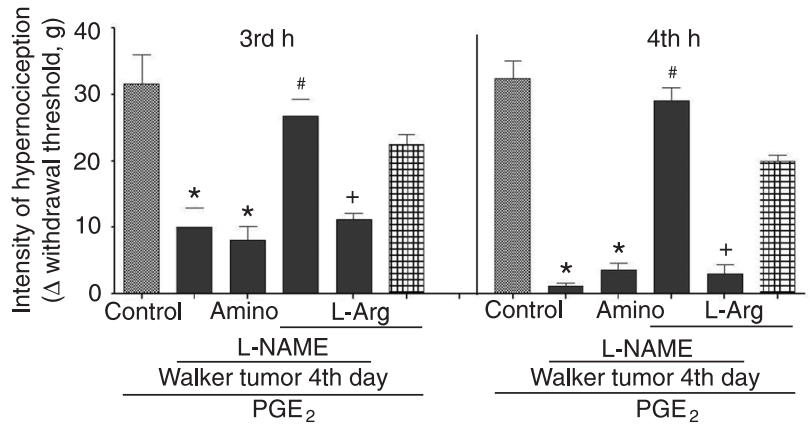

Figure 2. Involvement of nitric oxide in the antinociceptive effect induced by Walker tumor implantation. N $\omega_{\text {-nitro-L-arginine methyl }}$ ester (L-NAME; $90 \mathrm{mg} / \mathrm{kg} ; 0.5 \mathrm{~mL})$ or aminoguanidine $(10 \mathrm{mg} / \mathrm{kg} ; 0.2 \mathrm{~mL})$ was administered $1 \mathrm{~h}$ before prostaglandin $\mathrm{E}_{2}\left(\mathrm{PGE}_{2}\right)$ or carrageenan administration in the right paws of rats with (4th day after tumor implantation) or without tumor. L-arginine (L-Arg; 200 $\mathrm{mg} / \mathrm{kg} ; 0.5 \mathrm{~mL}$ ) was administered $10 \mathrm{~min}$ before L-NAME injection. The analgesic activity of Walker tumors in the right hind paw was measured 3 or $4 \mathrm{~h}$ after carrageenan- (Panel A) or $\mathrm{PGE}_{2}$-induced hypernociception (Panel $\left.\mathrm{B}\right)$. ${ }^{*} \mathrm{P}<0.05$ compared to saline group; ${ }^{\#} \mathrm{P}$ $<0.05$ compared to Walker tumor group; ${ }^{+} \mathrm{P}<0.05$ compared to Walker tumor + L-NAME group (ANOVA/Bonferroni test).
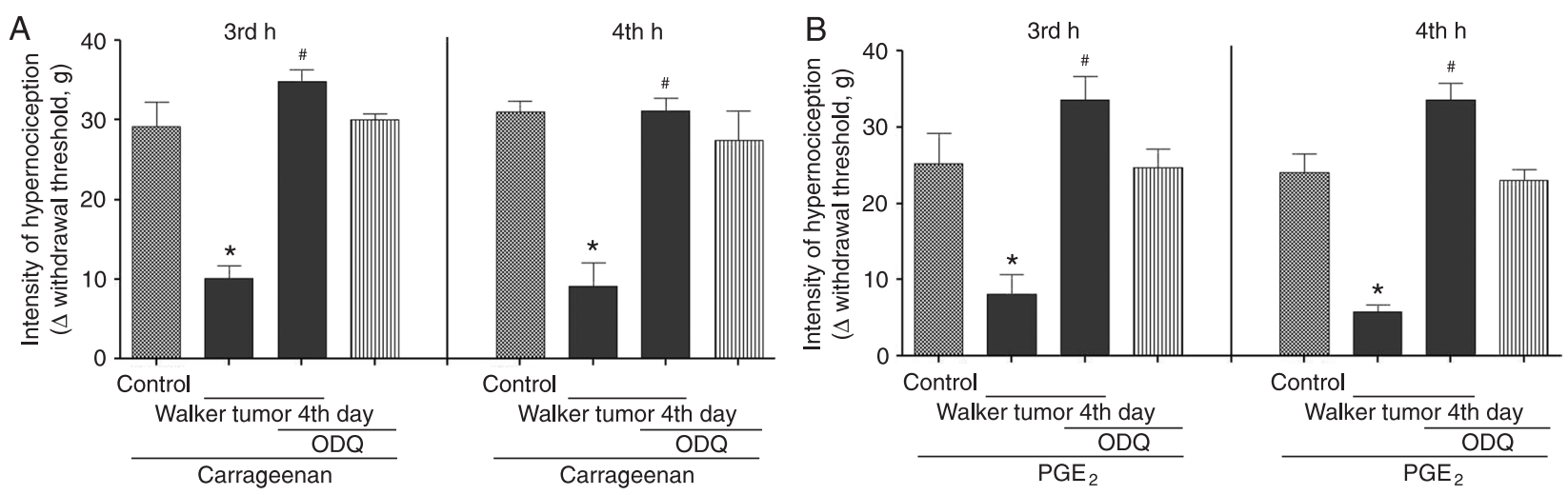

Figure 3. Involvement of cGMP in the antinociceptive effect induced by Walker tumor implantation. ${ }^{1} \mathrm{H}-[1,2,4]$-oxadiazolo[4,3-a]quinoxalin-1-one (ODQ) $(8 \mu \mathrm{g} / \mathrm{paw} ; 50 \mu \mathrm{L})$ was administered $30 \mathrm{~min}$ before carrageenan $(500 \mu \mathrm{g} / \mathrm{paw} ; 100 \mu \mathrm{L})$ or prostaglandin $\mathrm{E}_{2}\left(\mathrm{PGE}_{2}\right.$; $400 \mathrm{ng} / \mathrm{paw} ; 50 \mu \mathrm{L}$ ) administration in the right paws of rats with (4th day after tumor implantation) or without tumor. The analgesic activity of Walker tumors in the right hind-paw was measured 3 or $4 \mathrm{~h}$ after carrageenan (Panel A) or $\mathrm{PGE}_{2}$-induced hypernociception (Panel $B) . ~ \# P<0.05$ compared to Walker tumor group. ${ }^{*} P<0.05$ compared to saline group (ANOVA/Bonferroni test).
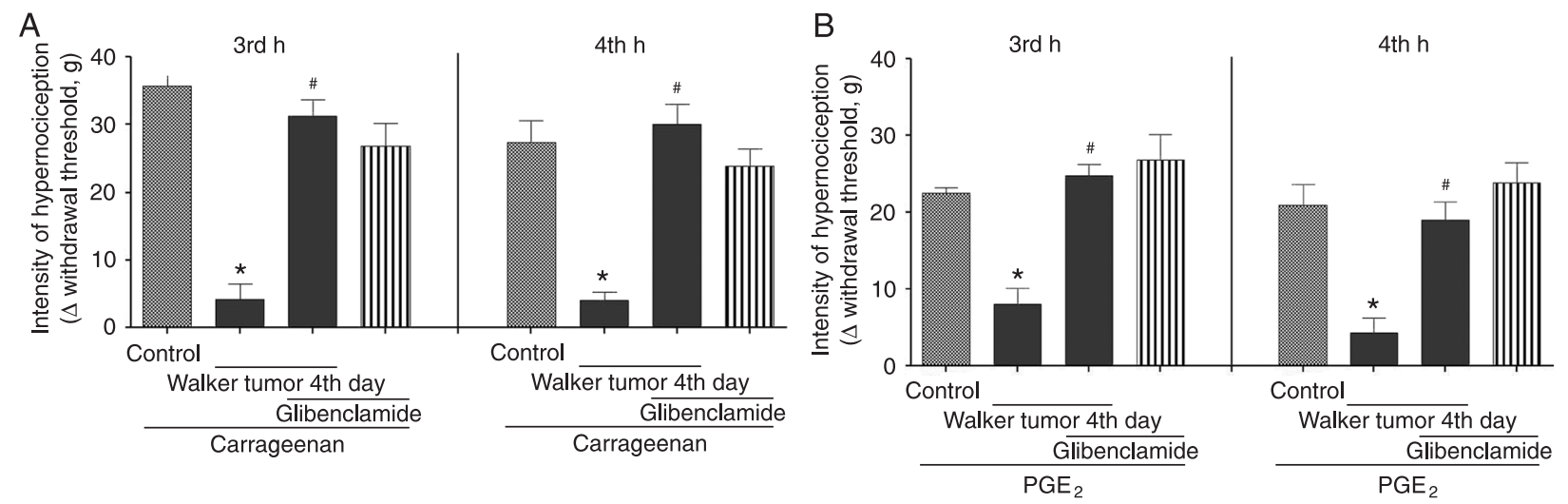

Figure 4. Involvement of ATP-sensitive $\mathrm{K}^{+}$(KATP) channels in the antinociceptive effect induced by Walker tumor implantation. Glibenclamide $(160 \mu \mathrm{g} / \mathrm{paw})$ was administered $30 \mathrm{~min}$ before carrageenan $(500 \mu \mathrm{g} / \mathrm{paw} ; 100 \mu \mathrm{L})$ or prostaglandin $\mathrm{E}_{2}\left(\mathrm{PGE}_{2} ; 400 \mathrm{ng} / \mathrm{paw}\right.$; $50 \mu \mathrm{L}$ ) administration to rats with (4th day after tumor implantation) or without tumor. The analgesic activity of Walker tumors in the right hind-paw was measured 3 or $4 \mathrm{~h}$ after carrageenan- (Panel A) or $\mathrm{PGE}_{2}$-induced (Panel B) hypernociception. $\# \mathrm{P}<0.05$ compared to Walker tumor group. ${ }^{*} \mathrm{P}<0.05$ compared to saline group (ANOVA/Bonferroni test). 
after treatment with carrageenan (Panel A, $3 \mathrm{~h}=87.5 \%, 4$ $\mathrm{h}=100 \%$ ) or $\mathrm{PGE}_{2}$ (Panel B, $3 \mathrm{~h}=100 \%, 4 \mathrm{~h}=85.6 \%$ ). In the control animals without tumors, glibenclamide did not increase the inflammatory hypernociception induced by either carrageenan (Panel A) or PGE 2 (Panel B).

\section{Discussion}

The influence of the tumor microenvironment on the acute systemic inflammatory response has not been clearly elucidated. Recently, our group demonstrated that Walker tumor bearing can limit mast cell function and vascular events in acute systemic inflammation models in rats, without changes in neutrophil migration (3). In the present study, our results demonstrate that Walker tumor bearing produced a peripheral antinociceptive effect in $\mathrm{PGE}_{2}$ - or carrageenan-induced mechanical hypernociception, and this effect was mediated at least in part by activation of the NO/cGMP pathway, followed by the opening of KATP channels.

The induction of inflammatory hypernociception is primarily driven by the sensitization of primary nociceptive neurons, an effect that is caused by nociceptor-sensitizing mediators. Our results demonstrated that Walker tumor implantation in the contralateral paw decreased both carrageenan- and $\mathrm{PGE}_{2}$-induced hypernociception. Carrageenan-induced hypernociception depends on the concomitant release and action of cytokines, which induces the subsequent release of IL-1 $\beta /$ prostanoids (16). On the other hand, $\mathrm{PGE}_{2}$, stimulated by cytokines, acts on nociceptive neurons by a direct mechanism (16-18). One possibility was that tumor bearing decreased the inflammatory response by decreasing cytokine release and, subsequently, inflammatory hypernociception. This hypothesis is consistent with our recent results, which demonstrated that Walker tumor bearing reduced carrageenan-induced paw edema (3). Published reports have demonstrated that the late edema phase induced by carrageenan depends on cytokine production by resident cells and neutrophil infiltration $(10,18)$. However, in our opinion, it is not the only mechanism involved in the tumor bearing-induced decrease in inflammatory hypernociception, as $\mathrm{PGE}_{2}$-induced hypernociception

\section{References}

1. Kim R, Emi M, Tanabe K. Cancer immunosuppression and autoimmune disease: beyond immunosuppressive networks for tumour immunity. Immunology 2006; 119: 254-264.

2. Meyers RL. Studies on tumor antigens of the Walker 256 carcinosarcoma. Immunochemistry 1975; 12: 589-595.

3. Barbosa AL, Pinheiro CA, Oliveira GJ, Moraes MO, Ribeiro $R A$, Vale $M L$, et al. Tumor bearing decreases systemic acute inflammation in rats - role of mast cell degranulation. Inflamm Res 2009; 58: 235-240.

4. Cunha TM, Verri WA Jr, Valerio DA, Guerrero AT, Nogueira was also decreased after Walker tumor implantation. We can infer that tumor bearing decreases both inflammation and hypersensitivity of nociceptive neurons.

We also provide evidence in the present study for the molecular mechanism by which tumor bearing promotes analgesia, i.e., stimulation of the $\mathrm{NO} / \mathrm{cGMP} / \mathrm{K}^{+} \mathrm{ATP}$ pathway. Our results clearly demonstrate that pretreatments with a nonspecific iNOS (L-NAME), guanylyl cyclase inhibitor (ODQ) and KATP blocker (glibenclamide) all reversed the antinociceptive effect induced by tumor bearing, suggesting that the NO/cGMP/K+ATP pathway plays a role in this response. The peripheral analgesic activity of the NO/cGMP pathway seems to result from the modulation of KATP currents. For instance, the peripheral antinociceptive effects of opioids, NO donors and CGMP are inhibited by KATP blockers (19-22). Our findings agree with literature reports that have demonstrated reversal of antinociceptive effects after inhibition of the NO/cGMP/K ${ }^{+}$ATP pathway (23-25).

Although we did not address the mechanism by which tumor bearing stimulates the peripheral NO analgesic pathway, there is evidence that systemic immunosuppression and angiogenic stimuli associated with malignant tumor growth could be mediated in part by mechanisms dependent on NO overproduction (26). This strengthens the hypothesis that the NO/cGMP/K+ATP pathway may be involved in tumor bearing-induced analgesia.

The present study showed an intrinsic peripheral antinociceptive action of Walker tumor bearing in rats. This antinociceptive effect seemed to be mediated by activation of the NO/cGMP pathway followed by the opening of KATP channels. This information may contribute to a better understanding of the effect of the tumor microenvironment on the inflammatory process, which could elucidate how malignant tumor growth can regulate nociceptive neurons, as well as tumor progression and invasion.

\section{Acknowledgments}

The authors gratefully acknowledge the technical assistance of Maria Silvandira Freire França. Research supported by CNPq. R.A. Ribeiro, M.O. Moraes and M.H.L.P. Souza are recipients of CNPq fellowships. 
7. Nakamura M, Ferreira SH. A peripheral sympathetic component in inflammatory hyperalgesia. Eur J Pharmacol 1987; 135: $145-153$.

8. Coussens LM, Werb Z. Inflammatory cells and cancer: think different! J Exp Med 2001; 193: F23-F26.

9. Nakayama T, Yao L, Tosato G. Mast cell-derived angiopoietin-1 plays a critical role in the growth of plasma cell tumors. J Clin Invest 2004; 114: 1317-1325.

10. Kulkarni SK, Mehta AK, Kunchandy J. Anti-inflammatory actions of clonidine, guanfacine and B-HT 920 against various inflammagen-induced acute paw oedema in rats. Arch Int Pharmacodyn Ther 1986; 279: 324-334.

11. Moncada S, Palmer RM, Higgs EA. Nitric oxide: physiology, pathophysiology, and pharmacology. Pharmacol Rev 1991; 43: $109-142$

12. Goldberg ND, Haddox MK, Nicol SE, Glass DB, Sanford $\mathrm{CH}$, Kuehl FA Jr, et al. Biologic regulation through opposing influences of cyclic GMP and cyclic AMP: the Yin Yang hypothesis. Adv Cyclic Nucleotide Res 1975; 5: 307-330.

13. Sachs D, Cunha FQ, Ferreira SH. Peripheral analgesic blockade of hypernociception: activation of arginine/NO/ cGMP/protein kinase G/ATP-sensitive $\mathrm{K}^{+}$channel pathway. Proc Natl Acad Sci U S A 2004; 101: 3680-3685.

14. Silva SL, Silva SF, Cavalcante RO, Mota RS, Carvalho RA, Moraes MO, et al. Mycophenolate mofetil attenuates Walker's tumor growth when used alone, but the effect is lost when associated with cyclosporine. Transplant Proc 2004; 36: 1004-1006.

15. Cunha TM, Verri WA Jr, Vivancos GG, Moreira IF, Reis S, Parada CA, et al. An electronic pressure-meter nociception paw test for mice. Braz J Med Biol Res 2004; 37: 401-407.

16. Cunha TM, Verri WA Jr, Silva JS, Poole S, Cunha FQ, Ferreira SH. A cascade of cytokines mediates mechanical inflammatory hypernociception in mice. Proc Natl Acad Sci U S A 2005; 102: 1755-1760.

17. Cunha FQ, Poole S, Lorenzetti BB, Ferreira SH. The pivotal role of tumour necrosis factor alpha in the development of inflammatory hyperalgesia. Br J Pharmacol 1992; 107: 660664.

18. Di Rosa M., Giroud JP, Willoughby DA. Studies on the mediators of the acute inflammatory response induced in rats in different sites by carrageenan and turpentine. J Pathol 1971; 104: $15-29$

19. Soares AC, Leite R, Tatsuo MA, Duarte ID. Activation of ATPsensitive $\mathrm{K}^{+}$channels: mechanism of peripheral antinociceptive action of the nitric oxide donor, sodium nitroprusside. Eur J Pharmacol 2000; 400: 67-71.

20. Ferreira SH, Duarte ID, Lorenzetti BB. The molecular mechanism of action of peripheral morphine analgesia: stimulation of the cGMP system via nitric oxide release. Eur J Pharmacol 1991; 201: 121-122.

21. Rodrigues AR, Duarte ID. The peripheral antinociceptive effect induced by morphine is associated with ATP-sensitive $\mathrm{K}^{+}$channels. Br J Pharmacol 2000; 129: 110-114.

22. Ortiz MI, Granados-Soto V, Castaneda-Hernandez G. The NO-cGMP-K ${ }^{+}$channel pathway participates in the antinociceptive effect of diclofenac, but not of indomethacin. Pharmacol Biochem Behav 2003; 76: 187-195.

23. Jesse CR, Savegnago L, Nogueira CW. Role of nitric oxide/ cyclic $\mathrm{GMP} / \mathrm{K}^{+}$channel pathways in the antinociceptive effect caused by 2,3-bis(mesitylseleno)propenol. Life Sci 2007; 81: 1694-1702.

24. Hernandez-Pacheco A, Araiza-Saldana Cl, Granados-Soto $\mathrm{V}$, Mixcoatl-Zecuatl T. Possible participation of the nitric oxide-cyclic GMP-protein kinase $\mathrm{G}-\mathrm{K}^{+}$channels pathway in the peripheral antinociception of melatonin. Eur J Pharmacol 2008; 596: 70-76.

25. Galdino GS, Cortes SF, Duarte ID, Perez AC. Involvement of the nitric oxide/(C)GMP/K(ATP) pathway in antinociception induced by exercise in rats. Life Sci 2010; 86: 505-509.

26. Hegardt $P$, Widegren $B$, Sjogren HO. Nitric-oxide-dependent systemic immunosuppression in animals with progressively growing malignant gliomas. Cell Immunol 2000; 200: 116127. 